\title{
Chemical composition, antinociceptive, anti-inflammatory and redox properties in vitro of the essential oil from Remirea maritima Aubl. (Cyperaceae)
}

\author{
Alessandra Silva Rabelo ${ }^{1}$, Mairim Russo Serafini ${ }^{1 *}$, Thallita Kelly Rabelo', Marcelia Garcez Dória de Melo', \\ Douglas da Silva Prado', Daniel Pens Gelain², José Claudio Fonseca Moreira², Marília dos Santos Bezerra', \\ Thanany Brasil da Silva ${ }^{3}$, Emmanoel Vilaça Costa ${ }^{3}$, Paulo Cesar de Lima Nogueira ${ }^{3}$, \\ Valéria Regina de Souza Moraes ${ }^{3}$, Ana Paula do Nascimento Prata ${ }^{4}$, Lucindo José Quintans Jr. ${ }^{1}$ \\ and Adriano Antunes Souza Araújo ${ }^{1}$
}

\begin{abstract}
Background: The present study was carried out to evaluate antioxidant, antinociceptive and anti-inflammatory activities of essential oil from R. maritima (RMO) in experimental protocols.

Methods: The essential oil from the roots and rhizomes of RMO were obtained by hydrodistillation using a Clevenger apparatus, and analyzed by gas chromatography/mass spectrometry (GC/MS). Here, we evaluated free radical scavenging activities and antioxidant potential of RMO using in vitro assays for scavenging activity against hydroxyl radicals, hydrogen peroxide, superoxide radicals, and nitric oxide. The total reactive antioxidant potential (TRAP) and total antioxidant reactivity (TAR) indexes and in vitro lipoperoxidation were also evaluated. The ability of RMO to prevent lipid peroxidation was measured by quantifying thiobarbituric acid-reactive substances (TBARS). NO radical generated at physiological pH was found to be inhibited by $\mathrm{RMO}$, that showed scavenging effect upon SNP-induced NO production at all concentrations. Antinociceptive and anti-inflammatory properties were evaluated by acetic acid writhing reflex, Formalin-induced nociception and Carrageenan-induced edema test.
\end{abstract}

Results: The majors compounds identified was remirol (43.2\%), cyperene (13.8\%), iso-evodionol (5.8\%), cyperotundone (5.7\%), caryophyllene oxide (4.9\%), and rotundene (4.6\%). At the TRAP assay, RMO concentration of $1 \mathrm{mg} \cdot \mathrm{mL}^{-1}$ showed anti-oxidant effects and at concentration of 1 and $10 \mathrm{ng} \cdot \mathrm{mL}^{-1} \mathrm{RMO}$ showed pro-oxidant effect. RMO at $1 \mathrm{mg} \cdot \mathrm{mL}^{-1}$ also showed significant anti-oxidant capacity in TAR measurement. Concentrations of RMO from $1 \mathrm{ng} \cdot \mathrm{mL}^{-1}$ to $100 \mu \mathrm{mg} \cdot \mathrm{mL}^{-1}$ enhanced the AAPH-induced lipoperoxidation. RMO reduced deoxyribose oxidative damage, induced by the Fenton reaction induction system, at concentrations from $1 \mathrm{ng} \cdot \mathrm{mL}^{-1}$ to $100 \mu \mathrm{g} \cdot \mathrm{mL}^{-1}$. We observed that RMO caused a significant increase in rate of adrenaline auto-oxidation. On the other hand RMO did not present any scavenging effect in $\mathrm{H}_{2} \mathrm{O}_{2}$ formation in vitro. The results of this study revealed that $\mathrm{RMO}$ has both peripheral and central analgesic properties. The RMO, all doses, orally (p.o.) administered significantly inhibited ( $p<0.05, p<0.01$ and $p<0.001)$ the acetic acid-induced writhings and two phases of formalin-induced nociception in mice.

Conclusion: The RMO demonstrated antioxidant and analgesic profile which may be related to the composition of the oil. Keywords: Remirea maritima, Essential oil composition, Redox properties

\footnotetext{
* Correspondence: maiserafini@hotmail.com

'Laboratório de Ensaios Farmacêuticos e Toxicidade, Universidade Federal de Sergipe (LeFT/UFS), 49100-000 São Cristóvão, Sergipe, Brazil

Full list of author information is available at the end of the article
} 


\section{Background}

The use of plants as a source of products for the treatment of diseases that affect mankind dates back to ancient ages. However, there are few plant species present in the literature with specifications for assessing the quality of the originating raw materials as well as validation methods that can be used for quantification of chemical markers which is essential for guaranteeing the efficacy and safety of the derived products [1]. In the last decades, the essential oils and various extracts of plants have been of great interest as they have been the sources of natural products [2].

Essential oils are mixture of volatile compounds (mainly mono- and sesquiterpenoids, benzenoids, amino acid- derivatives, phenypropanoids, etc.) with biological function on humans, animals, and other plants [3]. Nowadays, essential oils are not only popular as ingredients of perfumes, cosmetics, household cleaning products, foods and beverages, but because of its medicinal applications they have become useful in the treatment of different diseases due to their anticancer, anticonvulsant, anti-inflammatory, antimicrobial, analgesic, and antioxidant properties [4].

In recent years, there is an increasing interest in finding antioxidant phytochemicals, because they can inhibit the propagation of free radical reactions, protect the human body from diseases [5] and retard lipid oxidative rancidity in foods [6]. Free radicals and other reactive oxygen species (ROS), such as superoxide anion, hydroxyl radical, and hydrogen peroxide are an entire class of highly reactive molecules derived from the normal metabolism of oxygen or from exogenous factors and agents. Oxidative damage to crucial cellular molecules induced by ROS has been implicated as a possible factor in the etiology of several human diseases, including cancer, cardiovascular disease, and aging [7]. Another approach to natural product with antioxidant property is study in pain models [8].

In this context, plants have attracted the interest of many researchers and the pharmaceutical industry itself for being able to produce, transform, and accumulate numerous other substances, not necessarily directly related to the maintenance of cellular metabolism, called secondary metabolites [9]. Among the plants with promising biological activities based on the traditional use by the population, Remirea maritima Aubl. stands out, though studies involving this species are scarce in current literature. R. maritima Aubl. [Syn. Mariscus pedunculatus (R. Br.) T. Koyama] is a tropical Cyperaceae species popularly known as "capim-da-praia", which has been used traditionally to treat diarrhea, kidney disease, high fever, pain, and inflammations [10].

Previous reports on $R$. maritima include the isolation of flavones glycosides, cyperaquinones and phenolic ketones from the roots and rhizomes of the Cyperaceae [10-13], besides their antimicrobial activity of the dihydrocyperaquinone [12] and anti-inflammatory activity of the essential oil and the remirol [11]. Recently, we have shown that the aqueous extract of $R$. maritima features consistent analgesic and anti-inflammatory effects [13]. However, little is known through scientific literature about the pharmacological effects of the oil of this plant. In this sense, the study aimed to evaluate antioxidant, antinociceptive and anti-inflammatory activities of essential oil from $R$. maritima (RMO) in experimental protocols.

\section{Methods}

\section{Plant material}

R.maritima was collected in Pirambu city, Sergipe State, Brazil $\left(10^{\circ} 55^{\prime} \mathrm{S}, 35^{\circ} 6^{\prime} \mathrm{W}\right)$, and was identified by Dr. Ana Paula do Nascimento Prata (a plant taxonomist of the Department of Biology of the Federal University of Sergipe, São Cristovão, SE, Brazil). A voucher specimen has been deposited in the Herbarium of the Federal University of Sergipe (ASE/UFS) under $\mathrm{N}^{\mathrm{O}}$ 19013.The plant was collected in October 2010 and extracted few hours after collection.

\section{Hydrodistillation of the rhizomes and roots}

The essential oil from fresh roots and rhizomes of $R$. maritima (420 g) was obtained by hydrodistillation for $8 \mathrm{~h}$ using a Clevenger-type apparatus according to Siani et al. [11]. The RMO was dried over anhydrous sodium sulphate and the percentage content was calculated on the basis of the weight of plant material $(317.5 \mathrm{mg})$. The essential oil was stored in a freezer until GC/MS analysis.

\section{GC/MS analysis}

GC/MS analyses were performed on a Shimadzu QP5050A GC/MS system equipped with an AOC-20i auto-injector. A J\&W Scientific DB-5MS (coated with 5\%-phenyl-95\%dimethylpolysiloxane) fused capillary column (30 $\mathrm{m} \times$ $0.25 \mathrm{~mm} \times 0.25 \mu \mathrm{m}$ film thickness) was used as the stationary phase. Helium was the carrier gas at $1.2 \mathrm{~mL} \cdot \mathrm{min}^{-1}$ flow rate. Column temperatures were programmed from $40^{\circ} \mathrm{C}$ for $4 \mathrm{~min}$, raised to $220^{\circ} \mathrm{C}$ at $4^{\circ} \mathrm{C} \cdot \mathrm{min}^{-1}$, and then heated to $240^{\circ} \mathrm{C}$ at $20^{\circ} \mathrm{C}$. $\mathrm{min}^{-1}$. The injector and detector temperatures were $250^{\circ} \mathrm{C}$ and $280^{\circ} \mathrm{C}$, respectively. Samples $(1.0 \mu \mathrm{L}$ in ethyl acetate) were injected with a 1:20 split ratio. MS was taken at $70 \mathrm{eV}$ with a scan interval of $0.5 \mathrm{~s}$ and fragments from 40-350 Da. The retention indices [14] were obtained by co-injecting the oil sample with a $\mathrm{C}_{9}-\mathrm{C}_{18}$ linear hydrocarbon mixture (retention index from 1800-2100 range was obtained by extrapolation). The percentage composition of each component was determined by dividing the area of the componentby the total area of all components isolated under these conditions.

The volatile components were analyzed by GC/MS, and identification was made on the basis of standard compounds co-injection and comparison of retention 
indices and mass spectra with those in the literature [15] as well as by computerized matching of the acquired mass spectra with those stored in the NIST and Wiley mass spectral library of the GC/MS data system and other published mass spectra.

\section{Isolation and identification of major compounds of the essential oil}

Part of the crude essential oil (120 mg) from R. maritima was purified by preparative thin-layer chromatography (TLC) with hexane-EtOAc (95:5, v/v) as the mobile phase. The TLC was eluted three times to yield the fraction 1 (iso-evodionol $(7.4 \mathrm{mg}$ ), fraction 2 (remirol, $15.0 \mathrm{mg}$ ) and fraction 3 (cyperotundone, $2.0 \mathrm{mg}$ ). Fractions 1-3 were analyzed by GC/MS and also by ${ }^{1} \mathrm{H}$ and ${ }^{13} \mathrm{C}$ NMR spectroscopy on a BRUKER DRX 400 device using $\mathrm{CDCl}_{3}$ as a solvent and TMS as an internal standard.

\section{Total reactive antioxidant potential (TRAP) and total antioxidant reactivity (TAR)}

The total reactive antioxidant potential (TRAP) is employed to estimate the antioxidant capacity of samples in vitro. This method is based on the quenching of luminol-enhanced chemiluminescence (CL) derived from the thermolysis of 2,2'-azobis (2-amidinopropane) dihydrochloride (AAPH) as the free radical source [16].

The background $\mathrm{CL}$ was measured by adding $4 \mathrm{~mL}$ of AAPH $(10 \mathrm{mM})$ dissolved in glycine buffer $(0.1 \mathrm{M}$, $\mathrm{pH}$ 8.6) to a glass scintillation vial. Then, $10 \mu \mathrm{L}$ of luminol ( $4 \mathrm{mM}$ ) was added to each vial, and the CL was measured until constant light intensity. After this stabilization time, $10 \mu \mathrm{L}$ of Trolox solution or $10 \mu \mathrm{L}$ of sample was added, and the $\mathrm{CL}$ was measured in a liquid scintillator counter working in the out of coincidence mode. The AUC was calculated using Graph Pad Prism software.

\section{Thiobarbituric acid reactive species (TBARS)}

TBARS (thiobarbituric acid reactive species) assay was employed to quantify lipid peroxidation [17] and an adapted TBARS method was used to measure the antioxidant capacity of samples using egg yolk homogenate as lipid rich substrate [18]. Briefly, egg yolk was homogenized (1\% w/v) in $20 \mathrm{mM}$ phosphate buffer ( $\mathrm{pH} 7.4) ; 1 \mathrm{~mL}$ of homogenate was sonicated and then homogenized with $0.1 \mathrm{~mL}$ of sample at different concentrations. Lipid peroxidation was induced by addition of $0.1 \mathrm{~mL}$ of AAPH solution $(0.12 \mathrm{M})$. Control was incubation medium without AAPH. Reactions were carried out for $30 \mathrm{~min}$ at $37^{\circ} \mathrm{C}$. Samples $(0.5 \mathrm{~mL})$ were centrifuged with $0.5 \mathrm{~mL}$ of trichloroacetic acid (15\%) at $1200 \mathrm{~g}$ for $10 \mathrm{~min}$. An aliquot of $0.5 \mathrm{~mL}$ from supernatant was mixed with $0.5 \mathrm{~mL}$ TBA $(0.67 \%)$ and heated at $95^{\circ} \mathrm{C}$ for $30 \mathrm{~min}$. After cooling, samples absorbance was measured using a spectrophotometer at $532 \mathrm{~nm}$. The results were expressed as percentage of TBARS formed by AAPH alone (induced control).

\section{Nitric oxide ('NO) scavenging assay}

Nitric Oxide (NO) scavenging was generated from spontaneous decompositions of sodium nitroprusside in $20 \mathrm{mM}$ phosphate buffer ( $\mathrm{pH}$ 7.4). After incubation of the NO production system, Griess reagent was added and incubated for another $15 \mathrm{~min}$. The absorbance at $540 \mathrm{~nm}$ was determined by spectrophotometer [19].

\section{Hydroxyl radical $(\cdot \mathrm{OH})$ scavenging assay}

Hydroxyl radicals were generated by a Fenton system $\left(\mathrm{FeSO}_{2}-\mathrm{H}_{2} \mathrm{O}_{2}\right)$. When exposed to hydroxyl radicals, the sugar deoxyribose (DR) is degraded to malonaldehyde, which generates a pink chromogen on heating with thiobarbituric acid (TBA) at low pH. The method for determining the scavenging of hydroxyl radicals was performed according to a previously described procedure [20].

\section{Superoxide and hydrogen peroxide-scavenging activities (SOD/CAT-like activities)}

Superoxide radical scavenging based on generation of superoxide radical $\left(\mathrm{O}_{2}^{-}\right)$in the presence of NBT $(0.24 \mathrm{mM})$, glycine buffer $(50 \mathrm{mM})$, EDTA $(0.1 \mathrm{mM})$, and $(\mathrm{pH} 10.2)$ is compared with the effect of the compounds tested [21].

Catalase-like activity was determined by the concentration of $\mathrm{H}_{2} \mathrm{O}_{2}(0.02 \mathrm{mM})$ in phosphate buffer $(\mathrm{pH} 7.0)$ with absorbance at $240 \mathrm{~nm}$, following the method based on Aebi [22].

\section{In vivo experiments}

Animals. Male Swiss mice (25-30 g) were kept in a controlled-temperature room (mean temperature - standard deviation, $21^{\circ} \mathrm{C}-2^{\circ} \mathrm{C}$ ) with light/dark cycles of 12 hours each and were allowed free access to food (Purina chow) and water. Experimental protocols and procedures were approved by the Federal University of Sergipe Animal Care and Use Committee (no. 56/09).

\section{Acetic acid writhing reflex test}

This study was performed according to Koster et al. [23]. Mice ( $\mathrm{n}=8$, per group) were pretreated with RMO (50, 100 or 200 mg. $\mathrm{kg}^{-1}$, p.o.), acetylsalicylic acid (Aspirin, $200 \mathrm{mg} \cdot \mathrm{kg}^{-1}$ ), and the vehicle (saline + Tween-80 $0.2 \%$ ) by oral route (p.o.). Then, after $1 \mathrm{~h}$, the mice received the $0.85 \%$ acetic acid injection (i.p.). The writhing was counted for $15 \mathrm{~min}$ after a latency period of $5 \mathrm{~min}$.

\section{Formalin-induced nociception test}

The procedure described by Hunskaar and Hole [24] was used. Nociception was induced by injecting $20 \mu \mathrm{l}$ of $1 \%$ formalin in distilled water in the subplantar of the righthind paw. Mice $(n=8$, per group) previously received 
RMO (50, 100 or 200 mg. $\mathrm{kg}^{-1}$, p.o.), aspirin (200 mg. $\left.\mathrm{kg}^{-1}\right)$, and vehicle $1 \mathrm{~h}$ prior to injecting formalin. These mice were individually placed in a transparent plexiglass cage observation chamber $(25 \mathrm{~cm} \times 15 \mathrm{~cm} \times 15 \mathrm{~cm})$. The amount of time spent licking the injected paw was indicative of pain. The number of lickings from 0 to $5 \mathrm{~min}$ (early phase) and 15 to $30 \mathrm{~min}$ (late phase) were counted after injection of formalin [24].

\section{Evaluation of the motor activity}

Initially, the mice able to remain on the Rota-rod apparatus $\left(\mathrm{AVS}^{\oplus}\right.$, Brazil) longer than $180 \mathrm{~s}(9 \mathrm{rpm})$ were selected $24 \mathrm{~h}$ before the test [25]. Then, the selected animals were divided into five groups $(n=8$, per group) and treated p.o. with vehicle (control) or RMO (50, 100 or $200 \mathrm{mg} \cdot \mathrm{kg}^{-1}$ ). Each animal was tested on the rota-rod apparatus and the time (s) they remained on the bar for up to $180 \mathrm{~s}$ was recorded after 60,120 and180 min.

\section{Carrageenan-induced edema test}

Acute hind paw edema was produced by injecting $0.05 \mathrm{~mL}$ of carrageenan (1\%, prepared as a suspension indistilled water plus Tween 80 at $0.2 \%$ ) locally into the sub plantar aponeurosis of the right hind paw of mice [26]. Animals were divided into five groups, six rats per group. RMO was administered p.o. at different doses (50, 100, and $200 \mathrm{mg} \cdot \mathrm{kg}^{-1}$ ), indomethacin, standard drug, (INDO, $10 \mathrm{mg} . \mathrm{kg}^{-1}$, p.o.), and vehicle (p.o.) was given to a control group. RMO and INDO were administered $1 \mathrm{~h}$ prior to injection of carrageenan [27]. Paw volume was measured by dislocation of the water column of a plethysmograph (model EFF 304, Insight ${ }^{\oplus}$, Brazil) immediately after carrageenan application (time zero) and at 1, 2, 3, 4, 5 and $6 \mathrm{~h}$ after its administration.

\section{Statistical analyses}

The parameters data were evaluated by one-way ANOVA (analysis of variance) followed by the Tukey test. Differences were considered to be statistically significant when $p<0.05$. Data were evaluated using GraphPadPrism version 5.0 (GraphPad Prism Software Inc., San Diego, CA, USA).

\section{Results and discussion}

Hydrodistillation of the rhizomes and roots of $R$. maritima gave a yellow-orange essential oil (RMO), with a yield of $0.08 \%(w / w)$. As shown in Table 1 , it was possible to identify 32 compounds. The major compounds identified was remirol (43.2\%) as previously determined by Siani et al. [11]. However, in this work was possible verify that other compounds with concentration superior to $4 \%$ such as cyperene (13.8\%), iso-evodionol (5.8\%), cyperotundone (5.7\%), caryophyllene oxide (4.9\%), and rotundene $(4.6 \%)$ were present in the essential oil (Figure 1A and B). Fractions 1-3 were identified by comparing their NMR
Table 1 Essential oil composition of R. maritima

\begin{tabular}{|c|c|c|c|c|}
\hline & Compound & ${ }^{\mathrm{a}} \mathrm{RI}$ calc. & ${ }^{\mathrm{b}} \mathrm{RI}$ & $\%$ Peak area \\
\hline 1 & 1,8-cineole & 1030 & 1026 & 0.2 \\
\hline 2 & silphiperfol-4,7(14)-diene & 1363 & 1358 & 0.8 \\
\hline 3 & a-copaene & 1375 & 1374 & 0.8 \\
\hline 4 & $\beta$-elemene & 1390 & 1389 & 2.3 \\
\hline 5 & cyperene & 1405 & 1398 & 13.8 \\
\hline 6 & (E)-caryophyllene & 1419 & 1417 & 0.8 \\
\hline 7 & aromadendrene & 1447 & 1439 & 0.6 \\
\hline 8 & a-humulene & 1456 & 1452 & 0.3 \\
\hline 9 & rotundene & 1462 & 1457 & 4.6 \\
\hline 10 & y-gurjunene & 1474 & 1475 & 0.9 \\
\hline 11 & trans-cadina-1(6),4-diene & 1477 & 1476 & 0.8 \\
\hline 12 & $\beta$-selinene & 1489 & 1489 & 0.3 \\
\hline 13 & germacrene A & 1504 & 1504 & 0.3 \\
\hline 14 & $\delta$-cadinene & 1517 & 1522 & 0.3 \\
\hline 15 & a-bulnesene & 1504 & 1509 & 0.3 \\
\hline 16 & a-agarofuran & 1536 & 1537 & 1.9 \\
\hline 17 & guaia-6,9-dien-4 $\beta$-ol & 1567 & 1565 & 0.4 \\
\hline 18 & acora-3,5-dien-11-ol & 1574 & 1574 & 0.5 \\
\hline 19 & caryophyllene oxide & 1583 & 1582 & 4.9 \\
\hline 20 & humulene epoxide II & 1610 & 1608 & 0.9 \\
\hline 21 & acora-2,4(15)-dien-11-ol & 1613 & 1616 & 0.5 \\
\hline 22 & caryophylla-2(12),6-dien-5 $\beta$-ol & 1633 & 1633 & 0.5 \\
\hline 23 & cedr-8(15)-en-10-ol & 1651 & 1652 & 0.4 \\
\hline 24 & selin-11-en-4a-ol & 1659 & 1658 & 0.5 \\
\hline 25 & 14-hydroxy-9-epi-(E)-caryophyllene & 1970 & 1668 & 0.5 \\
\hline 26 & mustakone & 1674 & 1676 & 0.4 \\
\hline 27 & germacra-4(15),5,10(14)-trien-1a-ol & 1690 & 1685 & 0.6 \\
\hline 28 & cyperotundone & 1698 & $1695^{d}$ & 5.7 \\
\hline 29 & 14-hydroxy-humulene & 1719 & 1713 & 0.7 \\
\hline 30 & $\begin{array}{l}\text { 6-isopropenyl-4,8a-dimethyl- } \\
\text { 3,5,6,7,8,8a-hexahydro-2(1H)- } \\
\text { naphtalenone }\end{array}$ & 1789 & 1790 & 0.5 \\
\hline 31 & iso-evodionol & 1991 & $1962^{c, d}$ & 5.8 \\
\hline \multirow[t]{5}{*}{32} & remirol & 2047 & $2046^{c, d}$ & 43.2 \\
\hline & Monoterpenes & & & 0.2 \\
\hline & Sesquiterpenes & & & 45.8 \\
\hline & Benzenoids & & & 49.0 \\
\hline & Total Identified Compounds & & & 95.0 \\
\hline
\end{tabular}

${ }^{\mathrm{a}} \mathrm{RI}_{\text {calc, }}$, retention indices on DB-5MS column calculated according to ref. [14]. ${ }^{\mathrm{b}} \mathrm{Rl}$, retention indices according to ref. [15]. ${ }^{\mathrm{C}}$ retention index according to ref. [11]. ${ }^{d}$ co-injection with authentic standard.

$\left({ }^{1} \mathrm{H}\right.$ and ${ }^{13} \mathrm{C}$ ) (see Additional file 1) and GC/MS data with those reported in the literature $[11,28]$ as iso-evodionol, remirol and cyperotundone, respectively. This is 


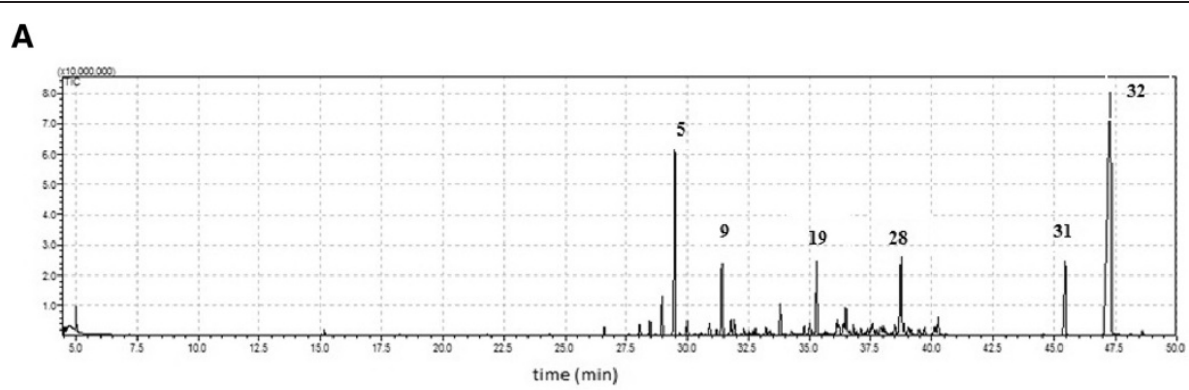

B

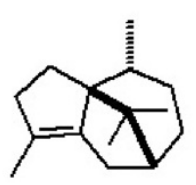

cyperene $(13.8 \%)$

(5)

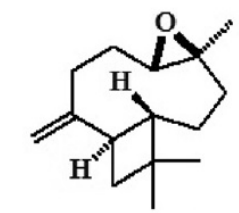

caryophyllene oxide ( $4.9 \%)$

(19)

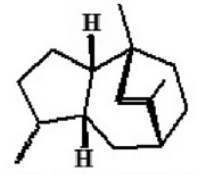

rotundene $(4.6 \%)$

(9)

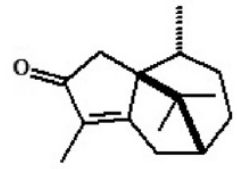

cyperotundone $(5.7 \%)$

(28)

Figure 1 A. GC/MS chromatogram of essential oil from roots and rhizomes of $\boldsymbol{R}$. maritima. Peak numbers corresponding to Table 1.

B. Chemical structures of major compounds identified in the essential oil of $R$. maritima. Peak numbers corresponding to Table 1.

the first report on isolation of cyperotundone from $R$. maritima.

The TRAP and TAR methods are widely employed to estimate the general antioxidant capacity of samples in vitro [29]. These methods were determined using a method based on the quenching of luminol enhanced chemiluminescence derived from the thermolysis of a water-soluble azo compound, AAPH, used as a reliable and quantify able source of alkyl peroxyl radicals. At the TRAP assay, RMO concentration of $1 \mathrm{mg} \cdot \mathrm{mL}^{-1}$ showed significant anti-oxidant effects and at concentration of 1 and $10 \mathrm{ng} \cdot \mathrm{mL}^{-1} \mathrm{RMO}$ showed pro-oxidant effect (Figure $2 \mathrm{~A}$ ). RMO at $1 \mathrm{mg} \cdot \mathrm{mL}^{-1}$ also showed significant anti-oxidant capacity in TAR measurement (Figure 2B).
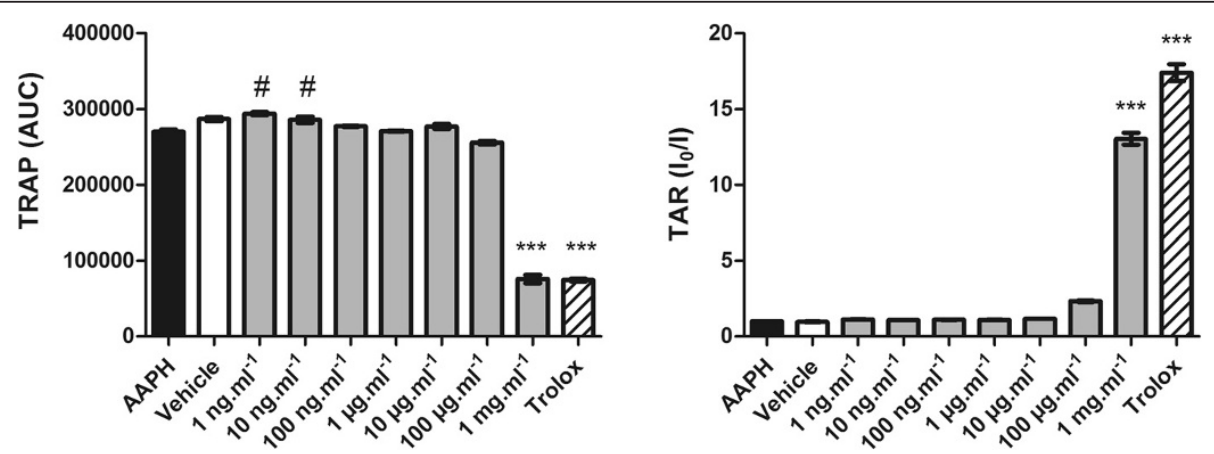

Figure 2 Total reactive antioxidant potential (TRAP) and total antioxidant reactivity (TAR). (A) TRAP analysis. A free radical source (AAPH) generates peroxyl radical at a constant rate, and the effect of different concentrations of RMO on free radical induced chemiluminescence is measured as area under curve during $60 \mathrm{~min}$. (B) TAR values are calculated as the ratio of light intensity in absence of samples (Ao)/light intensity right after RMO addition (A) and expressed as percent of inhibition. All groups denote samples in the presence of AAPH. Bars represent mean \pm SEM. ${ }^{* * *} p<0.0001$ antioxidant and \# pro-oxidant effect (1-way ANOVA followed by Tukey's multiple comparison post test). 
Lipid peroxidation has been defined as the biological damage caused by free radicals that are formed under oxidative stress [30]. The ability of RMO to prevent lipid peroxidation was measured by quantifying thiobarbituric acid-reactive substances (TBARS) generated by AAPH in a lipid-rich incubation medium. The effect of different concentrations on lipid peroxidation is shown in Figure 3. Concentrations of RMO from 1 ng.mL ${ }^{-1}$ to $100 \mu \mathrm{g} \cdot \mathrm{mL}^{-1}$ enhanced the AAPH-induced lipoperoxidation.

In this study, the ROM was checked for its inhibitory effect on nitric oxide production by the method of Griess. NO radical generated from sodium nitroprusside at physiological $\mathrm{pH}$ was found to be inhibited by ROM, that showed scavenging effect upon SNP-induced NO production at all concentrations (Figure 4).

The hydroxyl radical-scavenging capacity of a substance is directly related to its antioxidant activity. This radical has the capacity to join nucleotides in DNA and cause strand breakage, which contributes to carcinogenesis, mutagenesis, and cytotoxicity [31]. We observed that the RMO reduced deoxyribose oxidative damage, induced by the Fenton reaction induction system, at concentrations from 1 ng.mL ${ }^{-1}$ to $100 \mu \mathrm{g} \cdot \mathrm{mL}^{-1}$ (Figure 5).

The capacity of RMO to interact with and/or scavenge/quench $\mathrm{H}_{2} \mathrm{O}_{2}$ and superoxide radicals and in vitro was evaluated, respectively, by the catalase-like and the superoxide dismutase-like reaction assays. We observed that RMO caused a significant increase in rate of adrenaline auto-oxidation (Figure 6). On the other hand RMO did not present any scavenging effect in $\mathrm{H}_{2} \mathrm{O}_{2}$ formation in vitro (Figure 7 ).

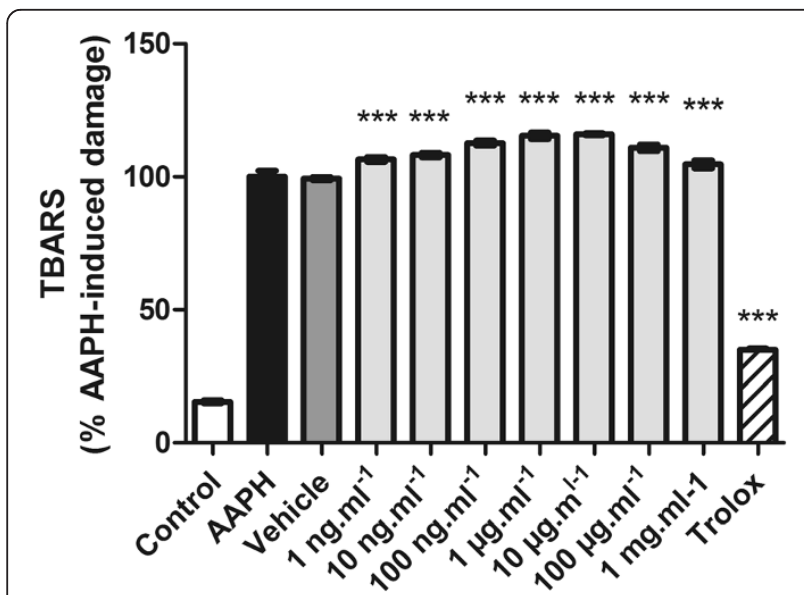

Figure 3 Thiobarbituric acid-reactive substances (TBARS)

in vitro. A lipid-rich system was incubated with a free radical source (AAPH) and the effect of different concentrations of RMO on the lipoperoxidation was measured by quantifying TBARS. Control is incubation medium without AAPH; other groups contained AAPH alone or in the presence of different concentrations of RMO or its vehicle alone. Bars represent mean \pm SEM. ${ }^{*} p<0.05,{ }^{* *} p<0.0001$ (1-way ANOVA followed by Tukey's multiple comparison post test).

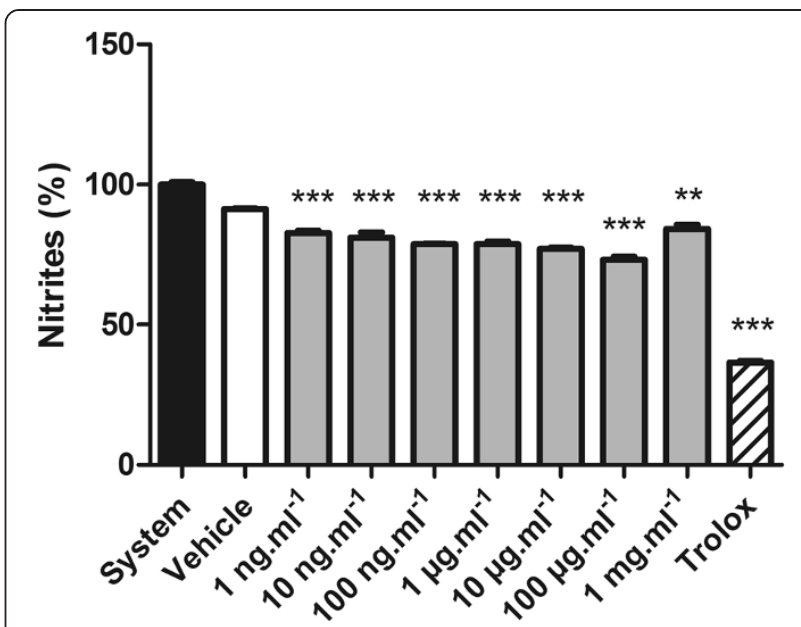

Figure 4 Nitric oxide radical scavenging activity of RMO. Values represent mean \pm standard error; experiments were performed in triplicate. Different concentrations of the RMO were incubated along with sodium nitroprusside. ${ }^{* *} p<0.001$ versus sodium nitroprusside (analysis of variance followed by Tukey test).

The results of this study revealed that RMO has both peripheral and central analgesic properties. The RMO, all doses, orally (p.o.) administered significantly inhibited $(\mathrm{p}<0.05, \mathrm{p}<0.01$ and $\mathrm{p}<0.001)$ the acetic acid-induced writhings and two phases of formalin-induced nociception in mice (Table 2). Those effects are probably relationship to the inhibition in the peritoneal fluid levels of $\mathrm{PGE}_{2}$ and $\mathrm{PGF}_{2 \alpha}$ [32] and with the release inhibition of substance P, and other inflammatory molecules, such as serotonin, histamine, bradykinin, and prostaglandins [33], respectively.

Previous studies suggested that the CNS depression and the non-specific muscle relaxation effect can reduce the response of motor coordination and might invalidate the behavior tests results [34]. We find that all RMO-treated

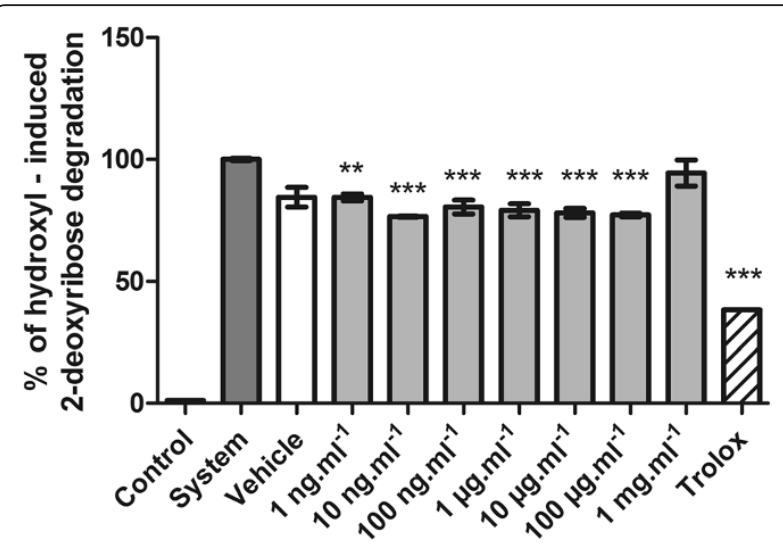

Figure $\mathbf{5}$ Hydroxyl radical-scavenging activity of RMO. Values represent mean \pm standard error; experiments were performed in triplicate. ${ }^{* *} p<0.01 ;{ }^{* * *} p<0.001$ versus system (analysis of variance followed by Tukey test). 


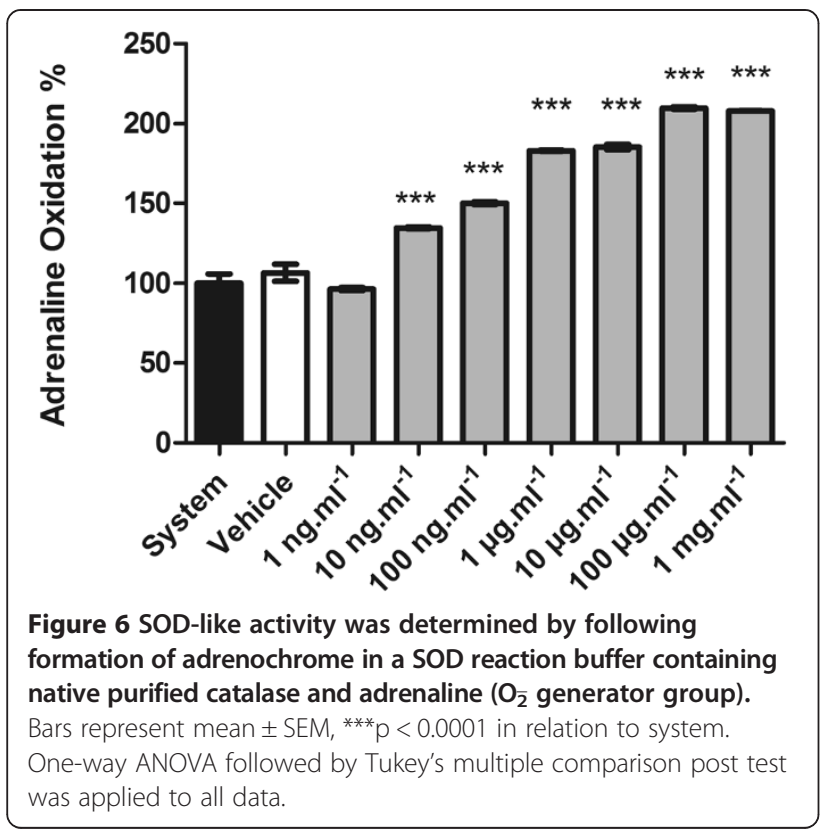

mice, at these doses, did nothave any performance alteration in the rota-rod apparatus (data no shown).

The initial phase of carrageenan paw edema is mediated by histamine and serotonin, while the mediatorsin the later phase are suggested to be arachidonate

metabolites (prostaglandins and leukotrienes) producing an edema dependent on the mobilization of neutrophils [35]. In our experiments, the edematous response was significantly suppressed in mice pretreated with RMO in the first phase of edema, suggesting an inhibitory effect on the release of histamine and/or serotonin (Figure 8). RMO showed a significant inhibition of edema in the second and third phases, suggesting

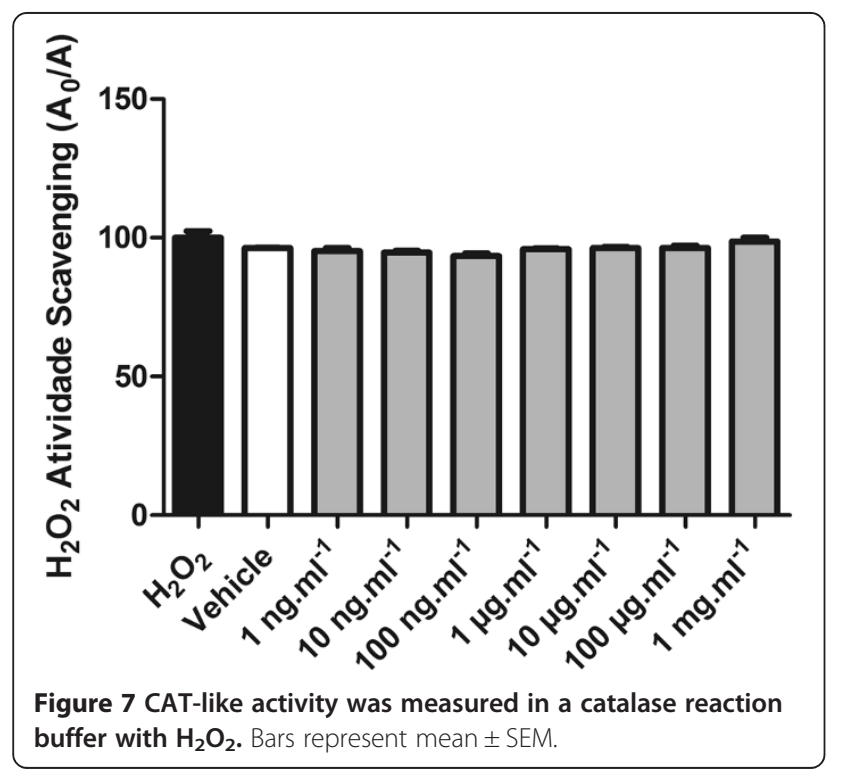

Table 2 Effect of RMO on writhing induced by acetic acid and formalin-induced nociception tests

\begin{tabular}{|c|c|c|c|c|}
\hline \multirow[t]{2}{*}{ Treatment } & \multirow[t]{2}{*}{ Dose $(\mathrm{mg} / \mathrm{kg})$} & \multirow{2}{*}{$\begin{array}{l}\text { Writhing test } \\
\text { Number of } \\
\text { writhings }^{\mathrm{a}}\end{array}$} & \multicolumn{2}{|c|}{ Formalin test } \\
\hline & & & $0-5 \min ^{a}$ & $15-30 \mathrm{~min}^{\mathrm{a}}$ \\
\hline Vehicle & - & $32.8 \pm 2.8$ & $56.3 \pm 5.2$ & $115.0 \pm 8.7$ \\
\hline $\mathrm{RMO}$ & 50 & $20.6 \pm 2.3^{b}$ & $43.0 \pm 2.92$ & $54.5 \pm 4.5^{\mathrm{d}}$ \\
\hline $\mathrm{RMO}$ & 100 & $18.1 \pm 3.6^{c}$ & $39.0 \pm 3.0$ & $54.8 \pm 4.3^{d}$ \\
\hline $\mathrm{RMO}$ & 200 & $10.1 \pm 2.5^{\mathrm{d}}$ & $31.3 \pm 5.69^{c}$ & $38.6 \pm 3.6^{d}$ \\
\hline Aspirin & 200 & $3.5 \pm 1.7^{d}$ & $40.1 \pm 4.9$ & $35.4 \pm 8.9^{d}$ \\
\hline
\end{tabular}

$n=8$, per group.

${ }^{a}$ Values represent mean \pm S.E.M.

${ }^{b} p<0.05,{ }^{c} p<0.01$ and ${ }^{d} p<0.001$ (one-way ANOVA and Tukey's test), significantly different from control group.

inhibition of 5-lipoxygenase and/or cyclooxygenase, both enzymes involved in the formation of prostaglandins and leukotrienes [34]. This edematous response was also significantly reduced in mice pretreated with indomethacin, a compound known to be a cyclooxygenase inhibitor.

Some studies suggest that antinociceptive and antiinflammatory effects, such as induced by RMO, could thus also be a consequence of its antioxidant ability, which may prevent the free radical-induced nuclear factor- $\mathrm{kB}$ activation and consequent pro-inflammatory cytokines production, a cycle that perpetuates inflammatory processes $[30,36]$.

\section{Conclusion}

This is the first complete report on the analysis of the volatile constituents from roots and rhizomes and isolation of cyperotundone from $R$. maritima. Their antioxidant activity of the oil essential of the $R$. maritima at $1 \mathrm{mg} \cdot \mathrm{mL}^{-1}$ showed significant anti-oxidant capacity in

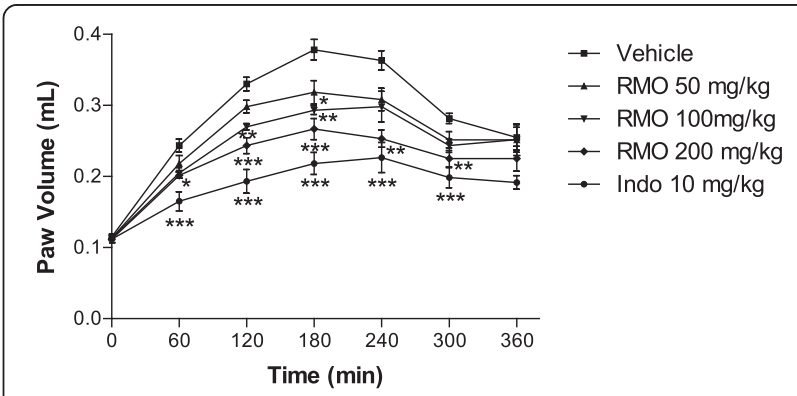

Figure 8 Effect of RMO or indomethacin (INDO) on mice paw edema induced by carrageenan. Mice were pretreated with vehicle, INDO (10 mg/kg), or RMO at the doses of 50, 100, and $200 \mathrm{mg} / \mathrm{kg}$ (v.o.) $60 \mathrm{~min}$ before carrageenan-induced paw edema. Measurements were performed at the times $0,1,2,3,4,5$ and $6 \mathrm{~h}$ after the subplantar injection of carrageenan $(1 \%, 50 \mu \mathrm{l})$. Each value represents the mean \pm S.E.M. Asterisks denote statistical significance, ${ }^{*} \mathrm{P}<0.05$, ${ }^{*} \mathrm{P}<0.01$, and ${ }^{*}{ }^{*} \mathrm{P}<0.001$, in relation to control group. ANOVA followed by Tukey's test. 
TAR as an increase in AAPH-induced lipoperoxidation at concentrations of from $1 \mathrm{ng} \cdot \mathrm{mL}^{-1}$ to $100 \mu \mathrm{g} \cdot \mathrm{mL}^{-1}$, also showing an inhibitory effect on nitric oxide production and in reducing deoxyribose oxidative damage, at concentrations of $1 \mathrm{ng} \cdot \mathrm{mL}^{-1}$ to $100 \mu \mathrm{g} \cdot \mathrm{mL}^{-1}$. The antinociceptive and anti-inflammatory activities relevant results demonstrated the essential oil from $R$. maritima observed both peripheral and central analgesic, the acetic acid-induced writhing and two phases of formalin-induced nociception in mice was significant at all doses $(\mathrm{p}<0.05, \mathrm{p}<0.01$ and $\mathrm{p}<0.001$ ), moreover the oil showed a significant inhibition of edema in the second and third stages of the test. The significant antioxidant activities of the essential oil confirm that this species is a natural source of biologically active compounds and could thus also be a consequence of the effects antinociceptive and anti-inflammatory of the oil essential the $R$. maritima. The present study adds more information to the ethnopharmacological knowledge of the plant and corroborates its use in Brazil.

\section{Additional file}

\section{Additional file 1:}

\begin{abstract}
Abbreviations
AAPH: 2,2'-Azobisisobutyramidinium chloride; ANOVA: Analysis of variance; AUC: Area under the curve; CAT: Catalase-like activity; $\mathrm{CL}$ : Chemiluminescense; CNS: Central nervous system; DR: Deoxyribose; EDTA: Ethylenediamine tetraacetic acid; GC: Gas chromatography; i. p.: Intraperitoneal; INDO: Indomethacin; MS: Mass spectrometry; NBT: Nitroblue tetrazolium; NO: Nitric oxide; p.o.: per os; RMO: Essential oil from R. maritima; ROS: Reactive oxygen species; SNP: Sodium nitroprusside; SOD: Superoxide dismutase; TAR: Total antioxidant reactivity; TBA: Thiobarbituric acid; TBARS: Thiobarbituric acid-reactive substances; TLC: Thin-layer chromatography; TRAP: Total reactive antioxidant potential.
\end{abstract}

\section{Competing interests}

The authors declare that they have no competing interests.

\section{Authors' contributions}

All authors took part in conception, design, collection, analysis, interpretation and writing of the manuscript. All authors participated in critical manuscript revision and approved the final manuscript.

\section{Acknowledgments}

The authors are grateful to CNPq, CAPES, and FAPITEC/SE for financial support and fellowships.

\footnotetext{
Author details

'Laboratório de Ensaios Farmacêuticos e Toxicidade, Universidade Federal de Sergipe (LeFT/UFS), 49100-000 São Cristóvão, Sergipe, Brazil. ${ }^{2}$ Centro de Estudos em Estresse Oxidativo, Departamento de Bioquímica, Instituto de Ciências Básicas da Saúde, Universidade Federal do Rio Grande do Sul, 13083-970 Porto Alegre, Rio Grande do Sul, Brazil. ${ }^{3}$ Laboratório de Pesquisa em Química Orgânica de Sergipe (LABORGANICS), Departamento de Química, Universidade Federal de Sergipe, 49100-000 São Cristóvão, Sergipe, Brazil. ${ }^{4}$ Laboratório de Sistemática Vegetal, Departamento de Biologia, Universidade Federal de Sergipe, 49100-000 São Cristóvão, Sergipe, Brazil.
}

Received: 5 November 2013 Accepted: 10 December 2014 Published: 23 December 2014

\section{References}

1. Khan IA: Issues related to botanicals. Life Sci 2006, 78:2033-2038

2. Edris AE: Pharmaceutical and therapeutic potentials of essential oils and their individual volatile constituents: a review. Phytother Res 2007, 21:308-323.

3. Dudareva N, Negre F, Nagegowda DA, Orlova I: Plant volatiles: recent advances and future perspectives. Crit Rev Plant Sci 2006, 25:417-440.

4. Bakkali F, Averbeck S, Averbeck D, Idaomar M: Biological effects of essential oils - a review. Food Chem Toxicol 2008, 46:446-475.

5. Kinsella JE, Frankel E, German B, Kanner J: Possible mechanisms for the protective role of antioxidants in wine and plant foods. Food Technol 1993, 47:85-89.

6. Duthie GG: Lipid peroxidation. Eur J Clin Nutr 1993, 47:759-764.

7. Halliwell B, Gutteridge JMC: Role of free radicals and catalytic metal ions in human diseases: an overview. Methods Enzymol 1990, 186:1-86.

8. Gouveia MGS, Xavier MA, Barreto AS, Gelain DP, Santos JPA, Araújo AAS, Silva FA, Quintans JSS, Agra MF, Cabral AGS, Tavares JF, Silva MS, QuintansJunior LJ: Antioxidant, antinociceptive, and anti-inflammatory properties of the ethanolic extract of Combretum duarteanum in rodents. $J$ Med Food 2011, 14:1389-1396.

9. Gobbo-Neto L, Lopes NP: Medicinal plants: factors of influence on the content of secondary metabolites. Quim Nova 2007, 30:374-381.

10. Allan RD, Correl RL, Wells RJ: A new class of quinones from certain members of the family Cyperaceae. Tetrahedron Lett 1969, 53:4669-4672.

11. Siani AC, Silva AMP, Nakamura MJ, De Carvalho MV, Henriques MGMO, Ramos MFS, Kaiser CR: Chemical composition and anti-inflammatory activity of the hydrodistillate from Mariscus pedunculatus. J Braz Chem Soc 2001, 12:354-359.

12. D'Albuquerque IL, De Lima OG, De Mello JF, Maciel GM, De Moraes e Souza MA: Antimicrobial compounds from higher plants. XXXIV: antimicrobial effect of dihydrocyperaquinone, isolated from Remirea maritima (Cyperaceae) growing on the north coast of Olinda. Rev Inst Antibiót Univ Fed Pernambuco 1971, 11:15-19.

13. Rabelo AS, Oliveira ID, Guimarães AG, Quintans JSS, Prata APN, Gelain DP, Venceslau EM, Santos JPA, Quintans-Júnior $\amalg$, Bonjardim LR, Barison A, Campos FR, Santos ADC, Nogueira PCL, Costa EV, Moraes VRS, Araújo AAS: Antinociceptive, anti-inflammatory and antioxidant activities of aqueous extract from Remirea maritima (Cyperaceae). J Ethnopharmacol 2013, 145:11-17.

14. Van Den Dool H, Kratz PD: A generalization of the retention index system including linear temperature programmed gas-liquid partition chromatography. J Chromatogr 1963, 11:463-471.

15. Adams RP: Identification of Essential Oil Components by Gas Chromatography/ Mass Spectrometry. 4th edition. Carol Stream: Allured Publ. Corp; 2007.

16. Dresch MT, Rossato SB, Kappel VD, Biegelmeyer R, Hoff ML, Mayorga P, Zuanazzi JA, Henriques AT, Moreira JC: Optimization and validation of an alternative method to evaluate total reactive antioxidant potential. Anal Biochem 2009, 385:107-114.

17. Draper $\mathrm{HH}$, Hadley M: Malondialdehyde determination as index of lipid peroxidation. Methods Enzymol 1990, 186:421-431.

18. Silva EG, Behr GA, Zanotto-Filho A, Lorenzi R, Pasquali MAB, Ravazolo LG, Bordignon CL Jr, Silva FA, Aboy AL, Bassani VL, Henriques AT, Dal-Pizzol F, Moreira JCF: Antioxidant activities and free radical scavenging potential of Bauhinia microstachya (RADDI) MACBR. (Caesalpinaceae) extracts linked to their polyphenol content. Biol Pharm Bull 2007, 30:1488-1496.

19. Payá M, Halliwell $B$, Hoult JRS: Interactions of a series of coumarins with reactive oxygen species: scavenging of superoxide, hypochlorous acid and hydroxyl radicals. Biochem Pharmacol 1992, 44:205-214.

20. Lissi E, Pascual C, Del Castillo MD: Luminol luminescence induced by 2,2'-azo-bis(2-amidinopropane) thermolysis. Free Radic Res Commun 1992, 17:299-311.

21. Basu S, Hazra B: Evaluation of nitric oxide scavenging activity, in vitro and ex vivo, of selected medicinal plants traditionally used in inflammatory diseases. Phytother Res 2006, 20:896-900.

22. Aebi H: Catalase in vitro. Methods Enzymol 1984, 105:121-126.

23. Koster R, Anderson M, Beer EJ: Acetic acid for analgesic screening. Fed Proceed 1959, 18:412-416.

24. Hunskaar S, Hole K: The formalin test in mice. Pain 1987, 30:103-104.

25. Rosland JH, Tjolsen A, Maehle B, Hole K: The formalin test in mice: effect of formalin concentration. Pain 1990, 42:235-242.

26. Winter CA, Riseley EA, Nuss GW: Carrageenin-induced edema in hind paw of the rat as an assay for anti-inflammatory drugs. Proc Soc Exp Biol Med 1962, 111:544-547 
27. Amresh G, Reddy GD, Rao CV, Singh PN: Evaluation of anti-inflammatory activity of Cissampelos pareira root in rats. Ethnopharmacol 2007, 110:526-531

28. Xu Y, Zhang H-W, Wan X-C, Zou Z-M: Complete assignments of (1)H and (13)C NMR data for two new sesquiterpenes from Cyperus rotundus L. Magn Reson Chem 2009, 47:527-531.

29. Melo MGD, dos Santos JPA, Serafini MR, Caregnato FF, Pasquali MAB, Rabelo TK, da Rocha RF, Quintans LJ Jr, Araújo AAS, da Silva FA, Moreira JCF, Gelain DP: Redox properties and cytoprotective actions of atranorin, a lichen secondary metabolite. Toxicol in Vitro 2011, 25:462-468.

30. Serafini MR, Santos RC, Guimaraes AG, dos Santos JPA, Santos ADC, Alves IA, Gelain DP, Nogueira PCL, Quintans-Júnior LJ, Bonjardim LR, Nogueira PCL, Araújo AAS: Morinda citrifolia Linn leaf extract possesses antioxidant activities and reduces nociceptive behavior and leukocyte migration. J Med Food 2011, 14:1159-1166.

31. Shukla S, Mehta A, Bajpai V, Shukla S: In vitro antioxidant activity and total phenolic content of ethanolic leaf extract of Stevia rebaudiana Bert. Food Chem Toxicol 2009, 47:2338-2343.

32. Deraedt $R$, Jouquey $S$, Delevallée F, Flahaut M: Release of prostaglandins $E$ and $F$ in an algogenic reaction and its inhibition. Eur J Pharmacol 1980, 61:17-24.

33. Tjolsen A, Berge O-G, Hunskaar S, Rosland JH, Hole K: The formalin test: an evaluation of the method. Pain 1992, 51:5-17.

34. Quintans-Júnior $\sqcup$, Melo MS, De Sousa DP, Araújo AAS, Onofre ACS, Gelain DP, Gonçalves JCR, Araújo DAM, Almeida JRGS, Bonjardim LR: Antinociceptive activity of citronellal in formalin-, capsaicin- and glutamate-induced orofacial pain in rodents and its action on nerve excitability. Orofac Pain 2010, 24:305-312.

35. Vinegar R, Truax JF, Selph JL, Johnston PR, Venable AL, McKenzie KK: Pathway to carrageenan-induced inflammation in the hind limb of the rat. Fed Proc 1987, 46:118-126.

36. Guimarães AG, Oliveira GF, Melo MS, Cavalcanti SCH, Antoniolli AR, Bonjardim LR, Silva FA, Santos JPA, Rocha RF, Moreira JCF, Araújo AAS, Gelain DP, Quintans-Júnior LJ: Bioassay-guided evaluation of antioxidant and antinociceptive activities of carvacrol. Basic Clin Pharmacol Toxicol 2010, 107:949-957.

\section{doi:10.1186/1472-6882-14-514}

Cite this article as: Rabelo et al:: Chemical composition, antinociceptive, anti-inflammatory and redox properties in vitro of the essential oil from Remirea maritima Aubl. (Cyperaceae). BMC Complementary and Alternative Medicine 2014 14:514.

\section{Submit your next manuscript to BioMed Central and take full advantage of:}

- Convenient online submission

- Thorough peer review

- No space constraints or color figure charges

- Immediate publication on acceptance

- Inclusion in PubMed, CAS, Scopus and Google Scholar

- Research which is freely available for redistribution 